\title{
The Properties and Host Range of Male-specific Bacteriophages of Pseudomonas aeruginosa
}

\author{
By VILMA A. STANISICH* \\ Department of Genetics, Monash University, 3168, Victoria, Australia
}

(Received 4 March 1974)

\begin{abstract}
SUMMAR Y
Three Pseudomonas aeruginosa phages specific for bacteria harbouring the P-group plasmid RPI have been isolated, and their properties compared with those of a previously described sex-specific phage, PRR I (Olsen \& Shipley, 1973). These phages are distinguishable from each other by various criteria, although in terms of host range to $\mathrm{FP}^{+}$and $\mathrm{RP}^{+}$lines of $P$. aeruginosa $\mathrm{PAO}$ they comprise broadly two groups. Thus all the phages infect bacteria harbouring any of a group of plasmids with similar properties to those of RPI, but whereas the filamentous phage $P_{3} 3$ is specific for this group, the host ranges of PRRI, $P_{3} 3$ and $P R_{4}$ are considerably wider. Nevertheless, with one exception, this does not extend to plasmids isolated outside the United Kingdom, which suggests that all these plasmids share a common ancestry even though by other criteria they constitute three fairly discrete subgroups. Of the plasmids that fail to allow phage propagation, three, when present in the same cell as RPI, reduce its susceptibility to phage infection. This inhibition may reflect a relationship between these elements, similar to that found among plasmids of Enterobacteria. A correlation is observed between the susceptibility of bacteria to phage infection and their ability to mediate plasmid transfer, such that these phages can conveniently be used to isolate both derepressed or transferdefective mutants of various $\mathrm{R}$ factors.
\end{abstract}

\section{INTRODUCTION}

The characteristics of $\mathrm{R}$ factors carried by clinical strains of Pseudomonas aeruginosa isolated from different geographical areas have been described by a number of investigators (Datta et al. 197I ; Stanisich \& Holloway, 197I ; Chabbert et al. 1972; Grinsted et al. 1972; Ingram et al. 1972; Kawakami et al. 1972; Saunders \& Grinsted, 1972; Bryan et al. 1973; Ingram, 1973; Morgan, Saunders, Stanisich \& Richmond, 1973; Olsen \& Shipley, 1973; Chandler \& Krishnapillai, 1974a, $b$; Stanisich, 1974). One of these strains, $P$. aeruginosa I822 (Lowbury et al. 1969), has been used widely in both inter- and intra-generic conjugations, and yields $R^{+}$transcipients resistant to the antibiotics carbenicillin (CB), neomycin/ kanamycin (NM/KM), and tetracycline (TC). The R factors carried by these sub-lines have been variously designated RPI (Grinsted et al. 1972), RP4 (Datta et al. 197I ; Holloway \& Richmond, I973), RI822 (Olsen \& Shipley, 1973) and RI8 (Chandler \& Krishnapillai, $1974 a$ ), and although isolated in independent experiments may well represent similar, if not identical, $\mathrm{R}$ factors. Olsen \& Shipley (1973) used the $\mathrm{RI}_{222^{+}}$sub-line to isolate an RNA-containing sex-specific phage, and this also infects bacteria harbouring RP4. The phage, designated PRRr, has physical characteristics similar to those described for the icosahedral RNA phages of Escherichia coli and P. aeruginosa (Olsen \& Thomas, 1973),

* Present address: Department of Bacteriology, Bristol University, Bristol BS8 ITD. 


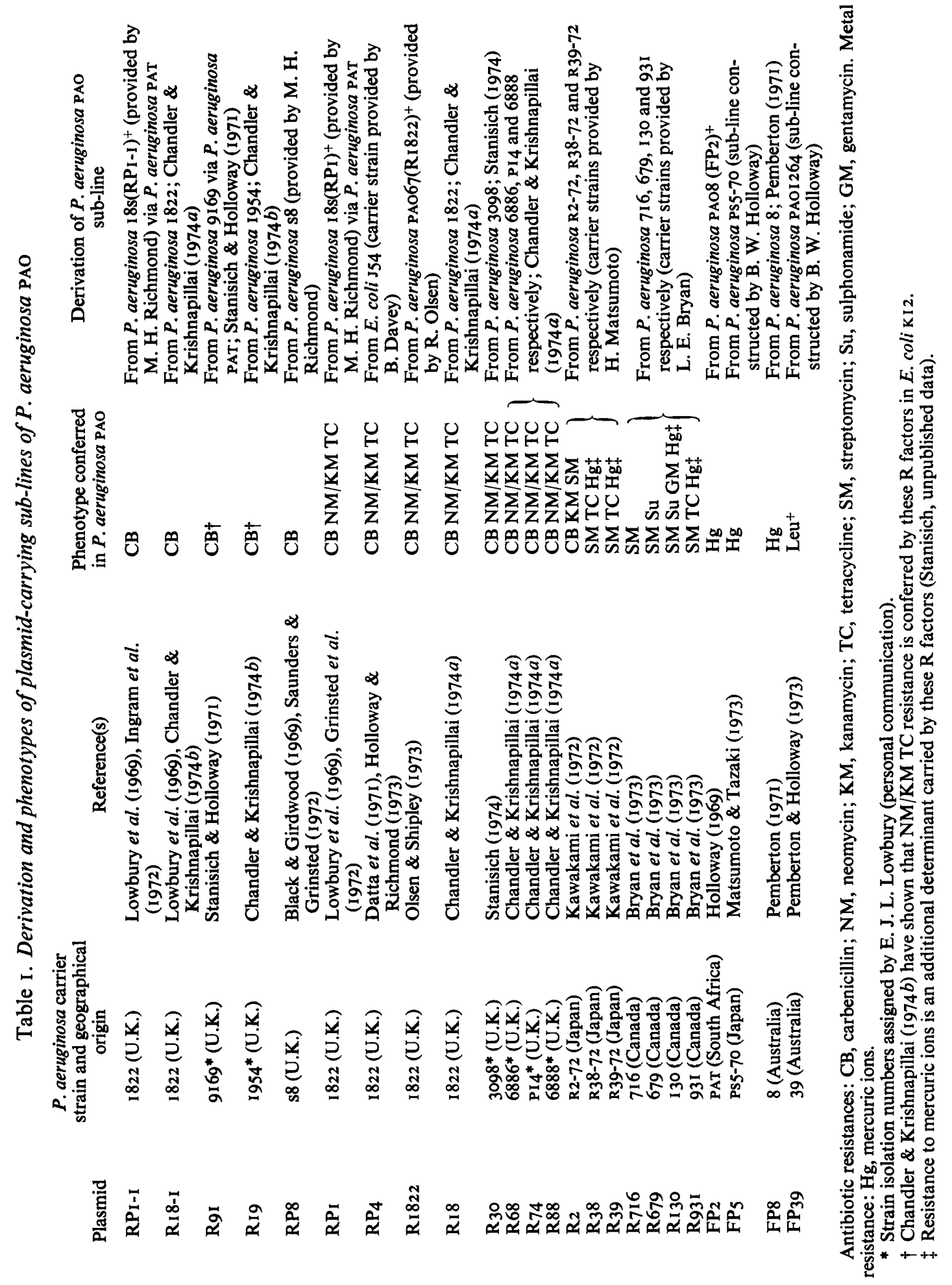


and like them shares a requirement for bacterial pili for adsorption (unpublished data of C. H. To and C. Brinton cited in Olsen \& Thomas, I973; Bradley, I974).

In the present investigation three phages specific for bacteria harbouring RPI have been isolated and their properties compared with those of PRRI. The ability of these phages to infect various plasmid-carrying derivatives of $P$. aeruginosa PAO was studied as a means of determining the genetic similarity, and hence possible relationships, between these plasmids. These include elements conferring resistance to antibiotics ( $R$ or $R P$ factors), as well as those initially detected because of their ability to mediate host chromosome transfer (FP factors). The use of these phages to isolate derepressed or transfer-defective mutants of the $\mathrm{R}$ factors was also investigated.

\section{METHODS}

Bacterial strains. All P. aeruginosa lines are derivatives of strain PAO (Holloway, 1969). These were: PAO8 met-28 ilv-202 str-I (Isaac \& Holloway, I968) and its sub-lines harbouring RPI-I, Ri8-I, Ri9, R9I, RP8, RPI, RP4, Ri822, Ri8, R30, R68, R74 or R88; PAOI670 leu-8 pur-I 36 chl-3 rif-I (Chandler \& Krishnapillai, 1974c) and its sub-lines harbouring R2, $\mathrm{R}_{38}$, R39, R716, R679, Rr30, R931, FP2, FP5, or FP39, or the 'double male' lines shown in Table 4 below; PAO3 ser-3 (Holloway collection) and its sub-line harbouring FP8. The derivation and phenotypes of the sub-lines are given in Table I. The double male strains were constructed from the appropriate PAOI670 lines and inherited RPI from PAO2604, i.e. PAO8 (RPI) ${ }^{+}$.

Escherichia coli $\mathrm{C}$ str (strain C4I I of Wiman, Bertani, Kelly \& Sasaki, I970) was obtained from P. M. Chandler and an $\mathrm{RPI}^{+}$sub-line constructed by mating with PAOI670 (RPI) ${ }^{+}$.

Escherichia coli $\mathrm{KI} 2 \operatorname{ton} B \operatorname{trp} \triangle A B$ was obtained from C. Yanofsky and an $\mathrm{RPI}^{+}$sub-line constructed by mating with PAO2604.

Abbreviations conform to the nomenclature of Demerec, Adelberg, Clark \& Hartman (I966).

Media. Nutrient broth (NB) and nutrient agar (NA) were as previously described (Stanisich \& Holloway, 1972). Supplements to NA were carbenicillin (Beecham Research Labs) and streptomycin (BDH), $250 \mu \mathrm{g} / \mathrm{ml}$, rifampicin (Ciba-Geigy), $200 \mu \mathrm{g} / \mathrm{ml}$, and mercuric chloride, I 5 to $30 \mu \mathrm{g} / \mathrm{ml}$.

Phage assay or plate mating by spot method. Sensitive bacteria or recipients for mating were seeded on to the surface of nutrient or selective medium by flooding the agar surface with several millilitres of a log phase culture, then removing the excess fluid. When the surface had dried, $0.01 \mathrm{ml}$ of serially diluted phage preparations or donor bacteria was spotted on to the lawn. Phage plaques or conjugal transcipients developed after 24 and $48 \mathrm{~h}$ respectively at $37^{\circ} \mathrm{C}$.

Multiplication of phage in liquid medium. Log phase cultures $\left(10^{7}\right.$ to $10^{8}$ bacteria/ml) were infected with phage at a final titre of $10^{4}$ to $10^{5}$ p.f.u. $/ \mathrm{ml}$. The mixture was incubated at $37^{\circ} \mathrm{C}$ with aeration for about $6 \mathrm{~h}$, then centrifuged and the phage titre of the supernatant determined.

Preparation of derepressed cultures. Log phase cultures of the recipient bacterium and its $\mathrm{FP}^{+}$or $\mathrm{RP}^{+}$sub-line were inoculated into $10 \mathrm{ml} \mathrm{NB}$ at a ratio of 50 or 100 to I respectively, and at an initial density of about $5 \times 10^{7}$ bacteria $/ \mathrm{ml}$. The mixture was incubated at $37^{\circ} \mathrm{C}$ with aeration for about $3 \mathrm{~h}$ or until the cell density had increased to about $10^{9} / \mathrm{ml}$.

Isolation of derepressed or transfer-defective $R$ factor mutants. Details of the mutagenesis procedure are described by Curtis, Richmond \& Stanisich (1973). Immediately after exposure to nitrosoguanidine, $R^{+}$cultures were mated with a recipient strain and the mixture plated to appropriate selective medium to isolate $R^{+}$transcipients. Derepressed mutants of 
R9I were isolated by cross-streaking single clones of such transcipients against PRRI (titre about $10^{9}$ p.f.u. $/ \mathrm{ml}$ ). Colonies that were phage-sensitive were selected as possible derepressed mutants. Non-siblings were those obtained from independent experiments. Transferdefective mutants of RPI were isolated by testing transcipients for their ability to transfer CB-resistance to a recipient by replica plate mating (Stanisich \& Holloway, 1972). Colonies that failed to yield CB-r progeny were selected as possible transfer-defective mutants.

Preparation of phage antiserum. Six injections of phage PRRI $\left(0.5\right.$ to $1.5 \mathrm{ml}$ of $2 \times 10^{10}$ p.f.u./ml) were made intravenously (except for the first which was intramuscular) at 3 to 4 day intervals. After resting the animal for one week, blood was collected and the serum separated by centrifugation after clot formation had occurred.

\section{RESULTS}

Isolation of bacteriophages specific for bacteria harbouring RPI

The isolation of RPI-specific bacteriophages from Melbourne, Australia, sewage followed a procedure similar to that described by Olsen \& Shipley (1973). Two bacterial strains were used, $P$. aeruginosa PAo (sensitive to streptomycin) and $E$. coli $\mathrm{C}$ (resistant to streptomycin), both harbouring the R factor RPI (Grinsted et al. 1972). Sewage effluent from two Melbourne localities was Millipore-filtered and samples plated to the $P$. aeruginosa indicator using the agar layer method (Adams, 1959). The plaques that developed after $24 \mathrm{~h}$ incubation at $37^{\circ} \mathrm{C}$ (about $40 / \mathrm{ml}$ ) were tested for lytic activity on the $E$. coli host by inoculating samples of the plaques to the indicator lawn on streptomycin-containing NA. Approximately $60 \%$ of the plaques tested produced lysis of both indicators, and further testing showed that the phages were specific for $\mathbf{R}^{+}$bacteria in that they failed to produce plaques on the $\mathbf{R}^{-}$parent strains. Three phages, which appeared to differ in plaque morphology, were chosen for further study and designated PR3 (from locality I) and PR4 and Pf (from locality 2). Their lytic activity on various hosts is shown in Table 2.

\section{Properties of R-specific bacteriophages}

Bradley (1974) has carried out a preliminary investigation of the four phages used in this study to determine their general morphology and sites of adsorption to $\mathrm{R}^{+}$hosts. The phages are of three types. PRRI is an isometric RNA-containing phage of approx. $26 \mathrm{~nm}$ diam, which adsorbs to R-coded pili in $E$. coli and is assumed to adsorb to similar structures in $P$. aeruginosa although these have yet to be demonstrated (Olsen \& Shipley, 1973; Olsen \& Thomas, 1973; unpublished data of C. H. To and C. Brinton cited in Olsen \& Thomas, 1973; Bradley, 1974). PR3 and PR4 are larger (approx. $65 \mathrm{~nm}$ diam) hexagonal-shaped virions, possibly with an easily detached tail, and these, in contrast to PRRI, adsorb to the cell wall of $\mathbf{R}^{+} E$. coli and $P$. aeruginosa. However, the possibility that very short or retractable pili provide the adsorption sites has not been disproved. $\mathrm{Pf}_{3}$ is a short filamentous virus (approx. $760 \mathrm{~nm}$ length) which also appears to infect the host directly through the cell wall rather than via R-coded pili (Bradley, I974).

A comparison of the plaque morphologies of these phages, produced after $\mathrm{I} 8 \mathrm{~h}$ growth in layers using an indicator such as $P$. aeruginosa $\mathbf{P A O}_{\mathrm{O}} 604$, allowed the filamentous $\mathrm{Pf}_{3}$ to be readily distinguished from the other phages. Thus $\mathrm{Pf}_{3}$ produces small (I to $\mathrm{I} \cdot 5 \mathrm{~mm}$ ) turbid plaques with ill-defined edges, in contrast to the clear, sharply defined plaques of the other phages. The turbidity of the former probably reflects the ability of $\mathrm{Pf}_{3}$-infected cultures to show a simultaneous increase, with time, of both phage titre and bacterial viable count, a characteristic common among filamentous phages (Marvin \& Hohn, 1969; Stanisich, 
Table 2. Lytic properties of $R$-specific bacteriophage on various bacterial hosts

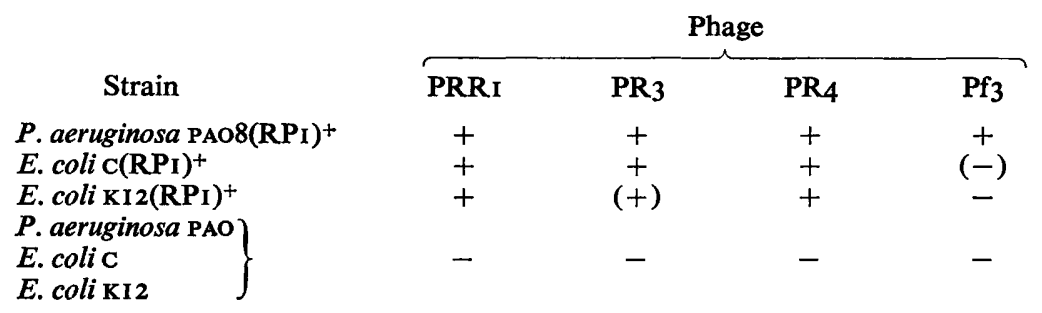

+ , Complete lysis at high phage titre $\left(>10^{4}\right.$ p.f.u. $\left./ \mathrm{ml}\right)$ and characteristic plaques at lower titre (see text); efficiency of plating (e.o.p.) on the various hosts is identical. $(+)$, Complete lysis at high phage titre ( $>10^{8}$ p.f.u./ml) but plaque size is markedly reduced in comparison to other hosts; e.o.p. may be reduced but this was difficult to determine. (-), Partial lysis at high phage titre, although individual plaques are not observed at lower titre. - , No lysis evident at phage titres of $10^{8}$ p.f.u. $/ \mathrm{ml}$.

unpublished data). The plaques of PRRI and PR4 are indistinguishable from each other, and both are considerably larger than those produced by $\mathrm{PR}_{3}$ ( 3 to $4 \mathrm{~mm}$ and $\mathrm{I}$ to $\mathrm{I} \cdot 5 \mathrm{~mm}$ respectively). A similar plaquing difference is seen when an $\mathrm{RPI}^{+}$line of $E$. coli $\mathrm{KI} 2$ is used as indicator (Table 2). PRRI and PR4 can be distinguished by their action on $P$. aeruginosa derivatives harbouring the $\mathrm{R}$ factor $\mathrm{R} 2$ (see below, Table 3 ). However, among other plasmidcarrying lines of $P$. aeruginosa the host range of these phages is identical.

Rabbit antiserum prepared against PRRI with an inactivation constant of II $\mathrm{min}^{-1}$ failed to inactivate any of the other phages even when undiluted antiserum was used. Although it is possible that some inactivation might occur with antiserum of greater potency, these results suggest a serological distinction between PRRI and the newly isolated $R$ specific phage. On these various criteria it is concluded that the four phages are not identical.

\section{Host range of the $R$-specific bacteriophages}

Plaque-forming ability. The transferable plasmids used in this study are harboured by three auxotrophic sub-lines of $P$. aeruginosa PAO: PAO8, PAOr670 and PAO3. Strain PAO is a particularly suitable host since a number of its plasmid-carrying derivatives are stable during about 15 generations' growth in non-selective medium (Stanisich \& Holloway, I971; Chandler \& Krishnapillai, I974a, $b$; Pemberton \& Holloway, 1973; Stanisich, 1974), and this is also true for the R factors RPI, RPI-I and RP8, those described by Bryan et al. (1973), Kawakami et al. (1972) and the FP factors FP5 and FP8 (Stanisich, unpublished data; P. Dry, personal communication). The geneology of the various derivatives and the characteristics conferred by the individual plasmids are shown in Table $\mathrm{I}$.

The host ranges of the RI822-specific phage PRRI and of the three RPI-specific phages $\mathrm{PR}_{3}, \mathrm{PR}_{4}$ and $\mathrm{Pf}_{3}$ were determined by spot phage assays on lawns of $\mathrm{RP}^{+}$and $\mathrm{FP}^{+}$bacteria on NA (Table 3). Only one series of plasmid-carrying bacteria acted as efficient hosts for the multiplication of these phages leading to plaque formation. This comprised bacteria harbouring the plasmids $\mathrm{RPI}_{1} \mathrm{RP}_{4}, \mathrm{R}_{1} 8$ and $\mathrm{R} \mathrm{B}_{822}$, all derived from $P$. aeruginosa $\mathrm{I} 822$, and $\mathrm{R}_{30}, \mathrm{R} 68, \mathrm{R}_{74}$ and $\mathrm{R} 88$, derived from $P$. aeruginosa strains isolated from the same clinical environment as $P$. aeruginosa 1822 (Lowbury et al. 1969; E. J. L. Lowbury, personal communication). The efficiency of plating (e.o.p.) of these phages was constant on the various $\mathrm{R}^{+}$hosts except for $\mathrm{R} 68$ which yielded turbid rather than clear plaques with an e.o.p. reduced ro- to roo-fold. This difference is probably associated with the slightly lower conjugal transferability observed with this $\mathbf{R}$ factor (Chandler \& Krishnapillai, I974a; 
Table 3. Host range of sex-specific phages on $\mathrm{FP}^{+}$and $\mathrm{RP}^{+}$lines of $P$. aeruginosa PAO

Plasmid carried by host bacterium*

RPI-I, RI8-I

RP8 R9I, RIg

RPI, RP4, RI8, RI822

R30, R68, R74, R88

R2

R38, R39

Ri30, R931

R679, R716

FP2, FP5, FP8, FP39
Plaque formation $\dagger$

$\begin{array}{cccc}\text { PRRI } & \text { PR3 } & \text { PR4 } & \text { Pf3 } \\ - & - & - & - \\ (+) & (+) & (+) & - \\ - & - & - & - \\ + & + & + & + \\ + & + & + & + \\ - & - & (+) & - \\ - & - & - & - \\ - & - & - & - \\ - & - & - & - \\ - & - & - & -\end{array}$

Increase in phage titre in liquid medium

$\begin{array}{cccc}\text { PRRI } & \text { PR3 } & \text { PR4 } & \text { Pf3 } \\ + & + & + & - \\ + & + & + & - \\ + & + & + & - \\ + & + & + & + \\ + & + & + & + \\ (+) & (+) & + & - \\ - & - & - & - \\ - & - & - & - \\ - & - & - & - \\ - & - & - & -\end{array}$

* For simplicity, the FP and RP factors are arranged in groups. These generally reflect the geographical origin of these elements (see Table I) or the groupings determined on the basis of plating of 'female-specific' phages (Krishnapillai, I974). The latter are in good agreement with the results obtained in other investigations.

$\dagger$ Determined by spot phage assay (see Methods). + , Single plaques at low phage titres; $(+)$, partial lysis at high phage titre but generally no plaques at lower titre; - , no lysis at high phage titre.

$\ddagger$ Procedure described in Methods. + , Increase in phage titre of $10^{3}$ to $10^{5} ;(+)$, increase in phage titre of Io- to 20-fold; -, no increase in phage titre.

also see below). The host range of PRRI is known to include RP4 $4^{+}$hosts (Olsen \& Shipley, 1973) so the cross-sensitivity observed within the first group of bacteria is perhaps not surprising. However, the identical behaviour of the second group suggests a similarity between the two. This has already been proposed by Chandler \& Krishnapillai (1974a) whose study of the latter group, and of RI8, indicated that these plasmids comprise a discrete collection, conferring a range of similar properties on their host cells. Most striking of these is the ability of these plasmids to infect bacteria of different genera, as has been particularly studied for RP4 (Datta et al. 1971; Datta \& Hedges, 1972) and RI822 (Olsen \& Shipley, 1973). Furthermore, the observation of both exclusion and incompatibility between RPI and the remaining plasmids (Stanisich, unpublished data) and their common ability to prevent multiplication of the temperate phage Gior (Krishnapillai, 1974) leaves little doubt that plasmids in this entire collection are closely similar.

Of the other $\mathrm{R}^{+}$bacteria studied only two, those harbouring R2 and RP8, showed evidence of lysis by these phages, though the response was variable and dependent on both cultural conditions and the particular sub-line employed. Thus at high phage concentrations, PRRI, PR3 and PR4 inhibited bacterial growth, but never completely, and if individual plaques were observed at lower concentrations these were generally extremely indistinct (Table 3).

Phage multiplication in liquid medium. In the preceding section the host range of the R-specific phages was determined by their gross lysis and plaque formation on plasmidcarrying bacteria. This procedure detects populations in which the majority of bacteria are sensitive to phage infection, but gives little information on those that appear 'resistant'. The latter could comprise bacteria that fail to act as host under any circumstances, or those that appear resistant because only a fraction of the population, at any particular time, is susceptible to infection. To distinguish between these two possibilities, combinations of the various phage and bacterial strains were cultured in liquid medium and the supernatants tested after a period of time to determine whether any increase in phage titre had occurred (Table 3). 
With the exception of the $\mathrm{R}_{2}{ }^{+}$host, all increases in phage titre were of the order $\mathrm{IO}^{3}$ to $\mathrm{IO}^{5}$. The host ranges of PRRI, PR 3 and PR4 extended to the entire series of hosts derived from the Lowbury collection, and their activity on RP8+ hosts was confirmed. Multiplication of all the phages was evident on $\mathrm{RPI}^{+}$hosts (and on the similar series of $\mathrm{R}^{+}$hosts), and it was of interest that Pf 3 was quite specific for this group. In contrast, neither the FP-carrying strains nor those harbouring $\mathrm{R} 38, \mathrm{R} 39$ or the $\mathrm{R}$ factors described by Bryan et al. (1973) acted as phage hosts. The results obtained with the $\mathbf{R 2}^{+}$line allow a distinction to be made between PR4 and the pair PRRI and PR3. It appears that some aspect of phage adsorption and/or multiplication occurs far more efficiently with $\mathrm{PR}_{4}$ leading to an increase in phage titre of $10^{2}$ to $10^{3}$ compared with an increase of only I0- to 20-fold with PRRI and PR3. One may conclude that RP8 and all the Lowbury R factors share properties that are necessary for the propagation of phages PRRI, PR 3 and PR4. At least some of these are also carried by R2, but not by any of the other RP or FP factors studied. The former two groups are, however, heterogeneous, and can be further subdivided on the basis of Pf 3 plating and the conditions under which phage multiplication can be detected.

Concerning the latter point, it is known that in P. aeruginosa PAO certain of the $\mathrm{R}$ factors, e.g. R9I and $\mathrm{R}_{3} 8$, are repressed for transfer function since populations newly inheriting these plasmids behave as more efficient donors (Chandler \& Krishnapillai, 1974 $b$; Stanisich, unpublished data). Such 'derepressed' populations of the various $\mathrm{FP}^{+}$and $\mathrm{RP}^{+}$strains, when tested for plaque formation by the R-specific phages, showed precisely the same lytic response as was found for their multiplication in liquid medium (Table 3). This suggests that the plasmids RPI-I, RI8-I, RP8, RI9, R9I and R2 differ from the RPI group in being repressed for those functions necessary for phage propagation, but that derepression can readily be effected by transfer of the plasmids to a new host.

\section{Relationship between phage susceptibility and plasmid transferability}

Three experimental approaches were employed to demonstrate a relationship between the susceptibility of $\mathrm{R}^{+}$bacteria to phage infection and their efficiency in promoting plasmid transfer. At least superficially, this relationship seems analogous to that described for certain plasmids of Enterobacteria (Meynell, Meynell \& Datta, I968).

Isolation of derepressed mutants by selection for bacteria sensitive to PRRI. R9I ${ }^{+}$derivatives of $P$. aeruginosa PAO are repressed for transfer function and show no evidence of lysis by the R-specific phages when tested on solid medium, in contrast to the results obtained with populations newly infected with this plasmid. Bacteria harbouring mutants of R9I, which were lysed by PRRI on solid medium, were isolated following the mutagenesis procedure of Curtis et al. (1973). Three non-sibling mutants were studied for their frequency of $\mathbf{R}$ factor transfer and for sensitivity to the other sex-specific phages.

In $25 \mathrm{~min}$ broth matings, using equal numbers of donor and recipient bacteria, transfer of the wild-type R9I occurred at frequencies of $10^{-2} /$ donor, whereas transfer of the mutant $\mathrm{R}$ factors was at an increased frequency of 0.5 to $\mathrm{I} /$ donor. Moreover, although plaquing of PRRI, PR 3 and PR4 was not evident on the R9I ${ }^{+}$host, the e.o.p. of these phages on the mutants and on an $\mathrm{RPI}^{+}$host was identical. In similar experiments, Chandler \& Krishnapillai ( $1974 b$ ) isolated derepressed mutants of RI9 and R9I by the method of Edwards \& Meynell (1968) and observed that in all instances increased $R$ factor transfer was accompanied by increased sensitivity to phage. It is therefore concluded that the same function(s) is required both for efficient plasmid transfer and phage susceptibility, or that these properties are under the same regulatory control.

Properties of phage-resistant and transfer-defective mutants of $R^{+}$bacteria. Bacteria 
Table 4. Phage susceptibility and $R$ factor transfer from double male strains of $P$. aeruginosa

Plasmid(s) harboured
by male strain
RPI
RPI.FP2
RPI.FP5
RPI.FP39
RPI.R38
RPI.R39
RPI.RI30
RPI.R716

Lysis by malespecific phages*

+
+
+
+
-
+
+

$$
\begin{gathered}
\text { Frequency of } \\
\text { RPI transfer } \dagger \\
1 \cdot 2 \times 10^{-8} \\
1 \cdot 1 \times 10^{-8} \\
<10^{-7} \\
\mathrm{I} \cdot 6 \times 10^{-2} \\
<10^{-7} \\
<10^{-7} \\
\mathrm{I} \cdot 0 \times 10^{-2} \\
9 \times 10^{-5}
\end{gathered}
$$

\footnotetext{
* Determined by spotting $10^{7}$ to $10^{8}$ p.f.u. of the four male-specific phages to lawns of the male bacteria. + , Complete lysis; - , no lysis; $(+)$, partial lysis.

+ Represents the frequency of CB-r transcipients recovered by spot plate matings.
}

harbouring RPI or a derepressed mutant of R9I were made resistant to one of the R-specific phages. Ten mutants of each resistance class showed cross-resistance to the remaining phages (not including Pf 3 in the case of R9I), and the transfer frequency of their R factors, as determined by spot plate matings, was invariably reduced in comparison with the parent strain. The reduction was however variable, ranging from $10^{-2}$ to $10^{-4}$ of the control level. Furthermore, 63 to 65 transfer-defective mutants of RPI, selected because of their low conjugal transfer of $\mathrm{CB}$ resistance (at least $10^{-4}$ of the wild-type level), showed resistance to all four sex-specific phages. The two sensitive strains retained sensitivity to all phages. These results are in accord with the conclusion of the preceding section, since they demonstrate that mutations affecting either phage plating or plasmid transfer generally produce concomitant changes in the alternate character.

Properties of double male strains. From Table 3 it was evident that the R factors R2, RP8 and those derived from the Lowbury collection were similar in their sensitivity to some or all of the R-specific phages. Although this similarity did not extend to $\mathbf{R}$ factors isolated outside the United Kingdom, nor to the four FP factors studied, an interaction was observed between RPI and several of these plasmids which simultaneously affected both phage sensitivity and plasmid transferability. Table 4 compares the properties of various double male strains harbouring RPI together with other FP and RP factors. Coexistence in the same cell with either $F_{5}, R_{3} 8$ or $R_{39}$ reduced the susceptibility of these $R_{P_{1}}{ }^{+}$bacteria to infection by sex-specific phage, and this reduced sensitivity was accompanied by a dramatic reduction in transferability of the RPI component. These same phenomena were observed with the other RPI-like elements, i.e. RP4, Ri822, R30, etc. (data not shown), supporting the previous conclusion that these plasmids are very similar. No such effect was apparent in the presence of $F_{2}, F_{39}$ or $\mathrm{R}_{130}$, although these plasmids coexist stably with RPI (Stanisich, unpublished data), but a slight inhibitory effect occurred with R716. The mechanisms by which these interactions are manifest are not yet clear; however, the important point is that once again an effect on phage plating was accompanied by a corresponding effect on plasmid transfer.

\section{DISCUSSION}

In this paper the isolation and properties of three sex-specific bacteriophages of $P$. aeruginosa have been described. By various criteria, including their electron microscopic characteristics (Bradley, 1974), these phages are distinguishable from each other and from the previously described sex-specific phage PRRI (Olsen \& Shipley, 1973; Olsen \& Thomas, 
1973). However, in terms of host range to $\mathrm{FP}^{+}$and $\mathrm{RP}^{+}$lines of $P$. aeruginosa PAo, they comprise broadly two groups: PRRI, PR3 and PR4 infect a variety of $R^{+}$hosts, whereas the filamentous Pf 3 is more restricted. With a single exception, that of the plasmid R2, only bacteria harbouring $\mathbf{R}$ factors isolated in the United Kingdom are susceptible to these phages. This finding is of interest as it suggests that this entire series of plasmids shares a common ancestry. Such a possibility is not unlikely since most of these elements were obtained from the same clinical environment, where the maintenance and interaction of plasmids would be favoured under the selective pressure provided by antibiotic usage. However, the three fairly discrete subgroups apparent from the phenotypic characteristics of these plasmids (Chandler \& Krishnapillai, I974a,b) is further supported by the plating responses to 'female-specific' phages (Krishnapillai, I974; T. Morgan, personal communication), and to a lesser extent to the male-specific phages. Thus RPI and its relatives are distinguishable from the two groups comprising RP8, RI9, R9I and RPI-I, RI8-I. In spite of these differences, studies of the DNA sequence homology of RPI-I, RP8 and RPI, which are representative of these subgroups, has revealed similarities (Ingram et al. 1972; Saunders \& Grinsted, 1972). Admittedly, in the case of RPI-I and RPI this may simply reflect similarity of the $\beta$-lactamase genes and those required for propagation of $\mathrm{R}$-specific phage, but between RP8 and RPI the I00\% homology suggests that all the sequences of RPI are represented in the larger molecule of RP8 (Saunders \& Grinsted, 1972).

This approach is undoubtedly the most satisfactory in establishing evolutionary relationships, since it overcomes the difficulty that similar phenotypic properties may merely reflect the identity of one or a small number of genes between otherwise quite dissimilar elements. For this reason it is difficult to assess the possible relationship between R2 and the U.K. isolates suggested by their susceptibility to R-specific phages and determination of $C B$ resistance, and that between $\mathrm{FP}_{5}, \mathrm{R}_{3} 8, \mathrm{R}_{39}$ and the RPI-like elements indicated by the inhibitory effect of the first three plasmids on the latter in double male strains. As far as has been studied, pairs of these elements show neither exclusion nor incompatibility with each other (Morgan et al. 1973; Stanisich, unpublished data), and the most obvious distinction (at least between $\mathbf{R}_{38}$, R39 and RPI) likely to result in the observed inhibition, is the repressed nature of plasmid transfer of R38 and R39 (Chandler \& Krishnapillai, r974a; Stanisich, unpublished data). Their interaction could therefore reflect a similarity of the repressor and operator genes controlling transferability of these plasmids, such as occurs between $\mathrm{fi}^{+} \mathbf{R}$ factors and F (Meynell et al. 1968). Although this commonly involves R factors that confer susceptibility to F-specific phages, exceptions are known (Grindley \& Anderson, 1971). However, other explanations are equally likely. For example, the presence of $R_{3} 8$ and $R_{39}$ reduces the susceptibility of $\boldsymbol{P}$. aeruginosa PAO to a variety of serologically unrelated phages (Krishnapillai, 1974), suggesting that these elements may cause changes in cell surface. Such an effect could indirectly inhibit RPI functions without indicating any genetic similarity between the plasmids.

Pseudomonas male-specific phages can be used to isolate transfer-defective and derepressed $\mathrm{R}$ factor mutants in a manner similar to that used with the male-specific phages of the Enterobacteria. It therefore seemed likely that the relationship between plasmid transferability and phage susceptibility could be an indirect one, stemming from a requirement for R-coded sex-pili for both these processes. This seems not to be the case from the electron microscope studies of Bradley (1974). Only PRRI is pilus-specific; the remaining phages, including the filamentous $\mathrm{Pf}_{3}$, apparently infect the cell directly through the cell wall. A dilemma arises when one considers that a single mutation can affect both plasmid transfer and susceptibility to all four R-specific phages, even though the latter may reflect changes at 
one of at least two possible adsorption sites - cell wall and pilus. It may be that a common component such as a pilin subunit is present at both sites and that this is an essential precursor for plasmid transfer. Adsorptional specificity could then be provided by the polymerized or unpolymerized state of the subunits at these locations.

I am grateful to those who kindly provided the bacterial strains and phage used in this study, and to Dr D. E. Bradley for valuable information, before publication, on the R-specific phages. My thanks to Professor B. W. Holloway and Dr V. Krishnapillai for suggestions during the preparation of this manuscript, and to Dr V. Krishnapillai for assistance in the preparation of phage antiserum. The gift of carbenicillin from Beecham Research Labs, rifampicin from Ciba-Geigy, and financial support from the Australian Research Grants Committee are gratefully acknowledged.

\section{REFERENCES}

ADAMs, M. (1959). Bacteriophages. New York: Interscience Publishing.

Black, W. A. \& GIRDWOod, R. W. A. (1969). Carbenicillin resistant Pseudomonas aeruginosa. British Medical Journal iv, 234.

BRADLEY, D. E. (1974). Adsorption of bacteriophages specific for Pseudomonas aeruginosa R factors RPI and RI822. Biochemical and Biophysical Research Communications 57, 893-900.

Bryan, L. E., Semaka, S. D., van de Elzen, H. M., Kinnear, J. E. \& Whitehouse, R. L. S. (1973). Characteristics of R93I and other Pseudomonas aeruginosa R factors. Antibiotic Agents and Chemotherapy 3 , 625-637.

Chabbert, Y. A., Scavizzi, M. P., Witchitz, J. L., Gerbaud, G. R. \& Bouanchaud, D. H. (1972). Incompatibility groups and the classification of $\mathrm{fi}^{-}$resistance factors. Journal of Bacteriology II2, 666-675.

Chandler, P. M. \& Krishnapillai, V. (I974a). Phenotypic properties of R factors of Pseudomonas aeruginosa: R factors readily transferable to Enterobacteriaceae. Genetical Research (in the Press).

Chandler, P. M. \& Krishnapillai, V. (1974b). Phenotypic properties of R factors of Pseudomonas aeruginosa: R factors transferable only within Pseudomonas. Genetical Research (in the Press).

CHANDleR, P. M. \& KRISHNAPILlaI, V. (1974c). Isolation and properties of recombination deficient mutants of Pseudomonas aeruginosa. Mutation Research 23, $15-23$.

Curtis, N. A. C., Richmond, M. H. \& Stanisich, V. A. (I973). R-factor mediated resistance to penicillins which does not involve a $\beta$-lactamase. Journal of Bacteriology 79, $163-165$.

Datta, N., Hedges, R. W., Shaw, E. J., Syxes, R. B. \& Richmond, M. H. (1971). Properties of an R factor from Pseudomonas aeruginosa. Journal of Bacteriology 108, I244-I 249.

Datta, N. \& Hedges, R. W. (1972). Host range of R factors. Journal of General Microbiology 70, 453-460.

Demerec, M., Adelberg, E. A., Clark, A. J. \& Hartman, P. E. (1966). A proposal for uniform nomenclature in bacterial genetics. Genetics $54,6 \mathrm{I}-76$.

Edwards, S. \& MeYNelL, G. G. (1968). General method for isolating derepressed bacterial sex factors. Nature, London 219, 869-870.

GrindLey, J. N. \& ANDERSON, E. S. (1971). I-like resistance factors with the $\mathrm{fi}^{+}$character. Genetical Research I7, 267-27I.

Grinsted, J., Saunders, J. R., Ingram, L. C., Sykes, R. B. \& Richmond, M. H. (1972). Properties of an $\mathrm{R}$ factor which originated in Pseudomonas aeruginosa 1822 . Journal of Bacteriology 110, 529-537.

Holloway, B. W. (1969). Genetics of Pseudomonas. Bacteriological Reviews 33, 419-443.

Holloway, B. W. \& Richmond, M. H. (1973). R factors used for genetic studies in strains of Pseudomonas aeruginosa and their origin. Genetical Research 21, 103-105.

INGRAM, L. C. (1973). Deoxyribonucleic acid-deoxyribonucleic acid hybridization of R factors. Journal of Bacteriology I15, I $130-1134$.

Ingram, L. C., Sykes, R. B., Grinsted, J., Saunders, J. R. \& Richmond, M. H. (I972). A transmissible resistance element from a strain of Pseudomonas aeruginosa containing no detectable extrachromosomal DNA. Journal of General Microbiology 72, 269-279.

IsaAC, J. H. \& HollowaY, B. W. (1968). Control of pyrimidine biosynthesis in Pseudomonas aeruginosa. Journal of Bacteriology 96, 1732-1 741 . 
Kawakami, Y., Mikoshiba, F., Nagasaki, S., Matsumoto, H. \& Tazaki, T. (1972). Prevalence of Pseudomonas aeruginosa strains possessing $\mathbf{R}$ factors in a hospital. Journal of Antibiotics 25, 607-609.

KRISHNAPILLAI, V. (1974). The use of bacteriophage in differentiating plasmids of Pseudomonas aeruginosa. Genetical Research (in the Press).

Lowbury, E. J. L., Kidson, A., Lilly, H. A., Ayliffe, G. A. \& Jones, R. J. (1969). Sensitivity of Pseudomonas aeruginosa to antibiotics: emergence of strains highly resistant to carbenicillin. Lancet ii, 448-452.

Marvin, D. A. \& HoHN, B. (1969). Filamentous bacterial viruses. Bacteriological Reviews 33, I $72-209$.

Matsumoto, H. \& TAZAKI, T. (1973). FP5 factor, an undescribed sex factor of Pseudomonas aeruginosa. Japanese Journal of Microbiology 17, 399-407.

Meynell, E., Meynell, G. G. \& DatTa, N. (1968). Phylogenetic relationships of drug-resistance factors and other transmissible bacterial plasmids. Bacteriological Reviews 32, 55-83.

Morgan, T., Saunders, J. R., Stanisich, V. A. \& Richmond, M. H. (1973). Compatibility relationships between $\mathbf{R}$ factors originally isolated from strains of Pseudomonas aeruginosa. Proceedings of the Journal of General Microbiology I, 13-14.

Olsen, R. H. \& ShIPley, P. (1973). Host range and properties of the Pseudomonas aeruginosa R factor Ri 822. Journal of Bacteriology 113, 772-780.

OLSEN, R. H. \& Thomas, D. D. (1973). Characteristics and purification of PRRI, an RNA phage specific for the broad host range Pseudomonas Rr822 drug resistance plasmid. Virology 12, I 560-I 567.

Pemberton, J. M. (197I). Conjugation in Pseudomonas aeruginosa. Ph.D. thesis, Monash University, Australia.

Pemberton, J. M. \& Holloway, B. W. (1973). A new sex factor of Pseudomonas aeruginosa. Genetical Research 2r, 263-272.

SAunders, J. R. \& GRINSTed, J. (1972). Properties of RP4, an R factor which originated in Pseudomonas aeruginosa s8. Journal of Bacteriology 112, 690-696.

STANISICH, V. A. (1974). Interaction between an $\mathrm{R}$ factor and an element conferring resistance to mercuric ions in Pseudomonas aeruginosa. Molecular and General Genetics 128, 201-212.

Stanisich, V. A. \& Holloway, B. W. (I971). Chromosome transfer in Pseudomonas aeruginosa mediated by $R$ factors. Genetical Research $\mathrm{r7}, 169-172$.

Stanisich, V. A. \& Holloway, B. W. (I972). A mutant sex factor of Pseudomonas aeruginosa. Genetical Research 19, 91-108.

Wiman, M., Bertani, G., Kelly, B. \& SASAKI, I. (1970). Genetic map of Escherichia coli strain c. Molecular and General Genetics 107, I-3I. 